\title{
Model Predictive Control Method with Constant Switching Frequency to Reduce Common-Mode Voltage for PMSM Drives
}

\author{
Hao Li, ${ }^{1}$ Shuo Chen, ${ }^{1}$ Xiang Wu $D^{1},{ }^{1}$ and Guojun Tan ${ }^{1,2}$ \\ ${ }^{1}$ School of Electrical and Power Engineering, China University of Mining and Technology, Xuzhou 86221008, China \\ ${ }^{2}$ China Mining Drives \& Automation Co., Ltd., Xuzhou 221008, China \\ Correspondence should be addressed to Xiang Wu; cumtwuxiang@qq.com
}

Received 19 April 2018; Revised 28 July 2018; Accepted 4 September 2018; Published 8 October 2018

Academic Editor: Antonio J. Marques Cardoso

Copyright (C) 2018 Hao Li et al. This is an open access article distributed under the Creative Commons Attribution License, which permits unrestricted use, distribution, and reproduction in any medium, provided the original work is properly cited.

A model predictive control method to reduce the common-mode voltage (MPC-RCMV) with constant switching frequency for PMSM drives is proposed in this paper. Four nonzero VVs are adopted in future control period and the switching sequence is designed to ensure the switching frequency is fixed and equal to the control frequency. By substituting the finite-control nonzero voltage vectors in the current predictive model, a current predictive error space vector diagram is obtained to determine the adopted four VVs. The duty ratio calculating method for the selected four VVs is studied. Compared with the conventional MPCRCMV method, the current and torque ripples are greatly reduced and the switching frequency is fixed. The simulation and experiment results validate the effectiveness of the proposed method.

\section{Introduction}

The common-mode voltage (CMV) of the permanent magnet synchronous motor (PMSM) drive system with two-level three-phase voltage source inverter (VSI), as shown in Figure 1 , can be approximately calculated according to the voltage between the midpoint of the dc-link capacitor and the neutral point of the three-phase load [1]. The high-frequency $\mathrm{CMV}$ can cause many problems including increasing the leakage currents [2], causing damage of the motor shaft [3], and increasing electromagnetic interference [4].

To address this problem, different solutions by improving the control strategy of the PMSM have been studied. In one aspect, many CMV reduction pulse-width modulation (CMVRPWM) strategies have been proposed [5-10]. The research results in [7] suggest that only the active zerostate PWM1 (AZSPWM1) [5] and the near-state PWM (NSPWM) [6] are practical in most cases among the earlier developed CMVRPWM strategies. In addition, the newly developed optimized CMVRPWM strategies with the consideration of the current ripple losses and switching losses minimizing have been proposed in [8]. All of the above CMVRPWM strategies can restrict the amplitude of the
CMV within sixth of the dc-link voltage. Some CMVRPWM strategies are proposed to reduce the low-order components of CMV [11, 12]. A virtual space vector PWM (VSVPWM) for the reduction of CMV in both magnitude and thirdorder component is studied in [13].

On the other hand, the model predictive control methods $[14,15]$ to reduce the CMV (MPC-RCMV) have also been proposed in [16-22]. The MPC-RCMV method proposed in [16] adopts only six nonzero voltage vectors (VVs) to calculate the cost function and the CMV amplitude is reduced without utilizing zero VVs. In [17], the optimal $\mathrm{VV}$ is selected from three adjacent nonzero VVs, and this MPC-RCMV method needs less compute efforts. However, it has been proven that many spikes may appear in the current ripple with the method in [17]. The problem has been analyzed in [18], and an improved MPC-RCMV method with four candidate VVs is developed to eliminate the current spikes. To eliminate the CMV spikes caused by the dead time, the method proposed in [19] preexcludes, from the candidates for future vectors, those voltage vectors which can increase the common-mode voltage during the dead time. A MPC-RCMV strategy without calculating the cost function is proposed in [20], where the nonzero optimal 


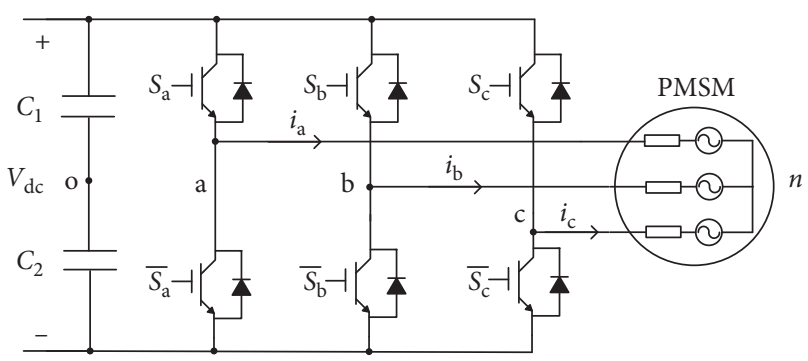

Figure 1: PMSM drive system with three-phase two-level VSI.

future VV is determined according to the basis of an inverse dynamics model. A two-vector based MPC-RCMV is proposed in [21], where two nonzero VVs are selected at every control period. The satisfactory load current ripple performance can be yielded; however, it is computationally intensive and the average switching frequency is still lower than $1 / T_{s}$. However, with these above MPC-RCMV strategies, the current and torque ripples may be larger than the conventional field-oriented control (FOC) $[23,24]$ with the same control frequency $\left(1 / T_{\mathrm{s}}\right)$, mainly owing to that the average switching frequency is far smaller than $1 / T_{s}$. In addition, the switching frequency of these methods are not fixed, which make it hard to analyze the harmonic features and design the filter. Many model predictive controllers with fixed switching frequency have been studied. The fixed switching frequency schemes for finite-control-set MPC are studied in $[25,26]$. Modulated MPC strategies [27, 28] have been developed to realize the target of constant switching frequency with the aid of a modulator. However, these fixed switching frequency MPC strategies in [25-28] have not considered the target of CMV reduction, and the amplitude of the CMV reaches to half of the dc-link voltages owing to the adoption of the zero VVs.

In this paper, a MPC-RCMV method with constant switching frequency is proposed. Unlike the conventional MPC-RCMV methods where one or two nonzero VVs are applied in future control period, four nonzero VVs are adopted and the switching sequence is designed to ensure the average switching frequency is fixed and equal to $1 / T_{\mathrm{s}}$. A current predictive error space vector diagram is obtained by substituting the finite-control nonzero VVs in the current predictive model, and according to it, the sector where the coordinate origin locates is calculated to determine the adopted four VVs. The duty ratio calculating method for the selected four VVs is studied. With the proposed method, the current reference can be fast and accurately tracked and the current ripples are much smaller than the conventional MPC-RCMV methods. Compared with the MPC methods with fixed switching frequency studied in [25-28], the proposed method can limit the amplitude of the CMV within sixth of the dc-link voltage. The effectiveness of the proposed method is validated by simulation and experiment.

\section{Conventional MPC-RCMV Method}

The conventional MPC-RCMV method for PMSM drives is shown in Figure 2. The current predictive model is given in the following equation:

$$
\left\{\begin{array}{l}
i_{\mathrm{q}}(k+1)=\frac{T_{\mathrm{s}}}{L_{\mathrm{q}}}\left[-R i_{\mathrm{q}}-\omega_{\mathrm{e}}\left(L_{\mathrm{d}} i_{\mathrm{d}}+\psi_{\mathrm{f}}\right)\right]+i_{\mathrm{q}}+\frac{T_{\mathrm{s}}}{L_{\mathrm{q}}} u_{\mathrm{q}}, \\
i_{\mathrm{d}}(k+1)=\frac{T_{\mathrm{s}}}{L_{\mathrm{d}}}\left[-R i_{\mathrm{q}}+\omega_{\mathrm{e}} L_{\mathrm{q}} i_{\mathrm{q}}\right]+i_{\mathrm{d}}+\frac{T_{\mathrm{s}}}{L_{\mathrm{d}}} u_{\mathrm{d}},
\end{array}\right.
$$

where $L_{\mathrm{d}}$ and $L_{\mathrm{q}}$ are the direct axis and quadrature axis inductances, $\psi_{\mathrm{f}}$ is the permanent magnet flux linkage, $i_{\mathrm{d}}, i_{\mathrm{q}}$, $u_{\mathrm{d}}$, and $u_{\mathrm{q}}$ are the load current and output voltage of the VSI at the $k$ th sampling instant, $i_{\mathrm{d}}(k+1)$ and $i_{\mathrm{q}}(k+1)$ are the predicted direct axis and quadrature axis currents at the $k+1$ th sampling instant, $R$ is the stator resistance, $T_{\mathrm{s}}$ is sample period, and $\omega_{\mathrm{e}}$ is angular speed.

To compensate the delay caused by the sampling and calculation in digital control, the typical method as proposed in $[29,30]$ is adopted, i.e., the direct axis and quadrature axis currents at the $k+2$ th sampling instant which are predicted as given in Equation (2) are adopted to calculate the cost function as Equation (3).

$$
\left\{\begin{aligned}
i_{\mathrm{q}}(k+2) & =\frac{T_{\mathrm{s}}}{L_{\mathrm{q}}}\left[-R i_{\mathrm{q}}(k+1)-\omega_{\mathrm{e}}\left(L_{\mathrm{d}} i_{\mathrm{d}}(k+1)+\psi_{\mathrm{f}}\right)\right]+i_{\mathrm{q}}(k+1)+\frac{T_{\mathrm{s}}}{L_{\mathrm{q}}} u_{\mathrm{q}}(k+1), \\
i_{\mathrm{d}}(k+2) & =\frac{T_{\mathrm{s}}}{L_{\mathrm{d}}}\left[-R i_{\mathrm{d}}(k+1)-\omega_{\mathrm{e}} L_{\mathrm{q}} i_{\mathrm{q}}(k+1)\right]+i_{\mathrm{d}}(k+1)+\frac{T_{\mathrm{s}}}{L_{\mathrm{d}}} u_{\mathrm{d}}(k+1), \\
J & =\left|i_{\mathrm{q}}^{*}-i_{\mathrm{q}}(k+2)\right|+\left|i_{\mathrm{d}}^{*}-i_{\mathrm{d}}(k+2)\right| .
\end{aligned}\right.
$$

For the MPC strategy, the voltage vector (VV) that minimized the cost function is chosen to be applied in the next control period. The difference between the conventional MPC and the MPC-RCMV method is the VV selection in the finite-control set. For the MPC-RCMV method, only nonzero VVs are included in the finite-control set to limit the amplitude of the CMV within sixth of the dc-link voltage. According to the number of the $\mathrm{VVs}$ in the finite-control set, the conventional MPC-RCMV methods can be divided into three categories as shown in Figure 3, i.e., the $6 \mathrm{VV}, 3 \mathrm{VV}$, and $4 \mathrm{VV}$ strategies. In Figure 3, the arrows define the possible changes of the switching states in the next control period. The finite-control set of $6 \mathrm{VV}$ strategy includes all the six nonzero VVs. As shown in 


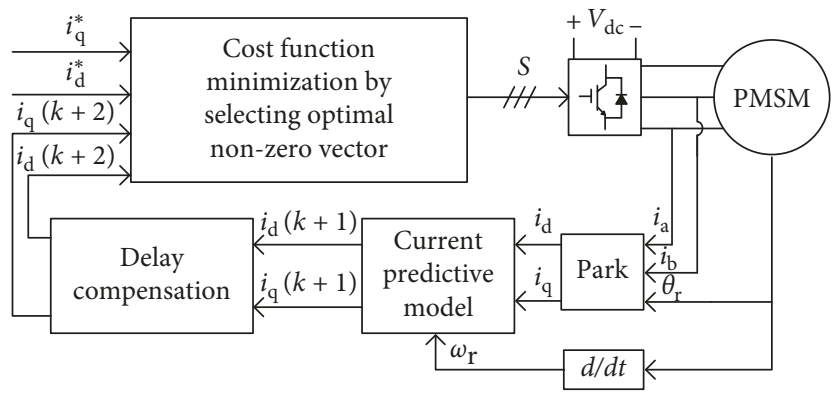

Figure 2: The control diagram of the conventional MPC-RCMV method.

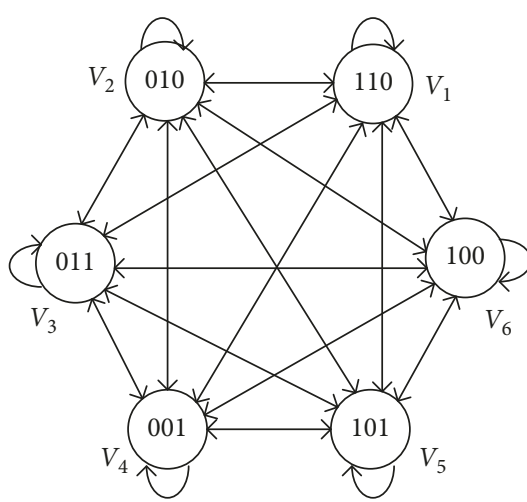

(a)

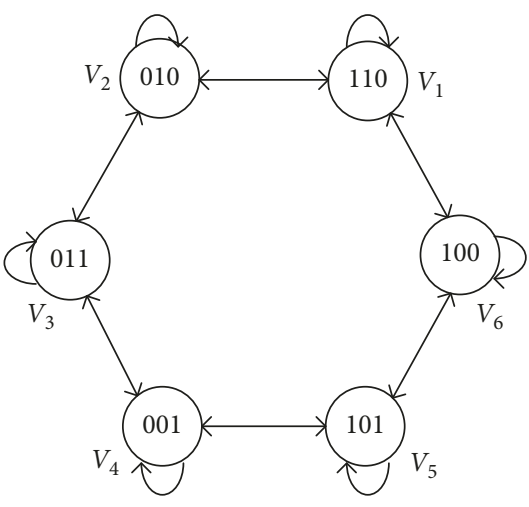

(b)

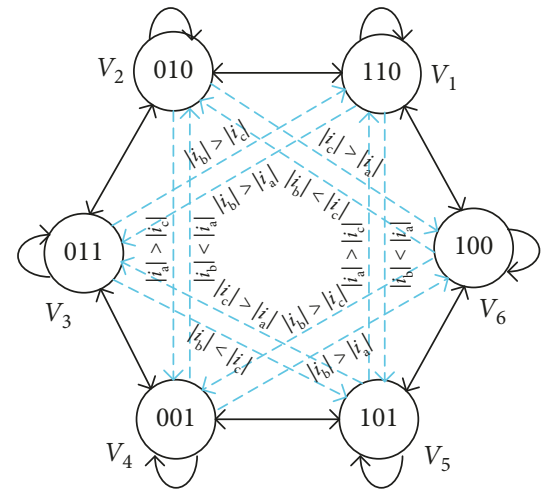

(c)

FIGURE 3: Switching state paragraph of the MPC-RCMV: the arrows define the possible changes of the switching states. (a) The $6 \mathrm{VV}$ strategy. (b) The $3 \mathrm{VV}$ strategy. (c) The $4 \mathrm{VV}$ strategy.

Figure 3(a), the optimal VV of the next control sample can be selected as any nonzero VV no matter which VV is applied in the current period. The switching frequency of the $6 \mathrm{VV}$ strategy is relatively high due to too many switches between nonadjacent VVs, e.g., all the power switches turn off or turn on with the switching state changing from 100 to 011. As shown in Figure 3(b), the finite-control set of $3 \mathrm{VV}$ strategy is determined by the VV applied in the current period and the number of the selectable VVs is 3 . The VV that applied in the current period and its two adjacent VVs can be selected for the next control period. Compared with the $6 \mathrm{VV}$ strategy, the switching frequency of the $3 \mathrm{VV}$ strategy is limited since at most one switch change is permitted, in addition, the computation amount is reduced by $50 \%$ owing to the number of cost function calculation changes from 6 to 3 . However, it has been proven that many spikes may appear in the current ripple when $3 \mathrm{VV}$ strategy is utilized due to the lack of enough alternative VVs [16]. To solve this problem, an improved $4 \mathrm{VV}$ strategy is developed in [16] where four VVs are chosen as candidate VVs at the same time as shown in Figure 3(c). Compared with the $3 \mathrm{VV}$ strategy, a nonadjacent VV is included in the finite-control set to ensure that the motor current can be adjusted towards two directions.

It should be noted that there are some problems for the conventional MPC-RCMV methods. Firstly, the switching frequency of these methods is not fixed, which makes the voltage and current spectrum spread over a wide range of frequencies. Secondly, the average switching frequency is smaller than the control frequency $\left(1 / T_{\mathrm{s}}\right)$ which should be set small enough considering the computation time, e.g., the results in [16] indicate that the average frequency of the $4 \mathrm{VV}$ strategy is no more than $2 \mathrm{kHz}$ with the control period set as $100 \mu \mathrm{s}$. Thus, the conventional MPCRCMV methods are not suitable in the fields where the average switching sequence needs to be high enough to realize the control targets such as decrease the torque ripples and the noises.

\section{Proposed MPC-RCMV Method with Constant Switching Frequency}

The control diagram of the proposed MPC-RCMV method with constant switching frequency is shown in Figure 4. It includes four parts, i.e., current predictive model, delay compensation, voltage vector selection and duty ratio calculation, and switching sequence producing part. Unlike the conventional MPC-RCMV method where only one active $\mathrm{VV}$ is applied in a single control period, the proposed method adopts 4 active VVs to keep the switching frequency fixed. The current predictive model part calculates $i_{\mathrm{d}}(k+1)$ and $i_{\mathrm{q}}(k+1)$ by Equation (4) where $u_{\mathrm{q}}^{\text {av }}$ and $u_{\mathrm{d}}^{\mathrm{av}}$ are the average $\mathrm{d}$ - and $\mathrm{q}$-axis voltages in the whole control period. The $u_{\mathrm{q}}^{\text {av }}$ and $u_{\mathrm{d}}^{\text {av }}$ can be calculated according to the selected 


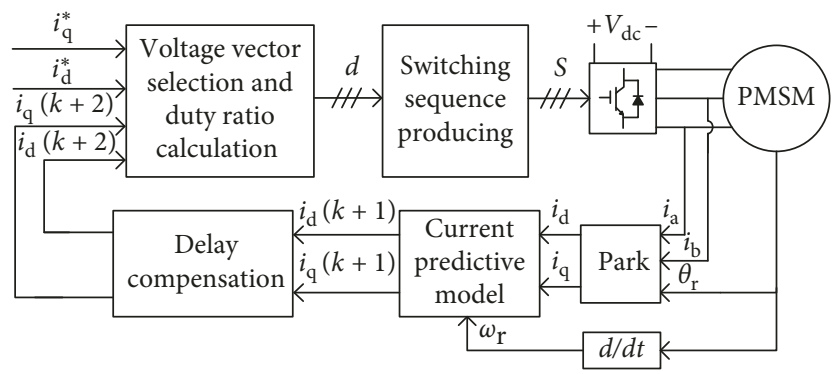

FIgURE 4: The control diagram of the proposed MPC-RCMV method with constant switching frequency.

VVs and their duty ratios which are obtained in the last control period by the proposed MPC-RCMV method.

$$
\left\{\begin{array}{l}
i_{\mathrm{q}}(k+1)=\frac{T_{\mathrm{s}}}{L_{\mathrm{q}}}\left[-R i_{\mathrm{q}}-\omega_{\mathrm{e}}\left(L_{\mathrm{d}} i_{\mathrm{d}}+\psi_{\mathrm{f}}\right)\right]+i_{\mathrm{q}}+\frac{T_{\mathrm{s}}}{L_{\mathrm{q}}} u_{\mathrm{q}}^{\mathrm{av}} \\
i_{\mathrm{d}}(k+1)=\frac{T_{\mathrm{s}}}{L_{\mathrm{d}}}\left[-R i_{\mathrm{q}}+\omega_{\mathrm{e}} L_{\mathrm{q}} i_{\mathrm{q}}\right]+i_{\mathrm{d}}+\frac{T_{\mathrm{s}}}{L_{\mathrm{d}}} u_{\mathrm{d}}^{\mathrm{av}}
\end{array}\right.
$$

Then, the direct axis and quadrature axis currents at the $(k+2)$ th sampling instant for different active VVs can be calculated by substituting Equation (4) in Equation (2).

The predictive current errors (PCE) are defined as

$$
\left\{\begin{array}{l}
e_{\mathrm{id}}=i_{\mathrm{d}}(k+2)-i_{\mathrm{d}}^{*}, \\
e_{\mathrm{iq}}=i_{\mathrm{q}}(k+2)-i_{\mathrm{q}}^{*} .
\end{array}\right.
$$

By combining Equations (2) and (4), the PCE equation can be written as

$$
\left\{\begin{array}{l}
e_{\mathrm{id}}=C_{\mathrm{d}}+\frac{u_{\mathrm{d}}(k+2) T_{\mathrm{s}}}{L_{\mathrm{d}}} \\
e_{\mathrm{iq}}=C_{\mathrm{q}}+\frac{u_{\mathrm{q}}(k+2) T_{\mathrm{s}}}{L_{\mathrm{q}}}
\end{array}\right.
$$

where $C_{\mathrm{d}}$ and $C_{\mathrm{q}}$ satisfy

$$
\left\{\begin{array}{l}
C_{\mathrm{d}}=\frac{T_{\mathrm{S}}}{L_{\mathrm{d}}}\left[-R i_{\mathrm{d}}(k+1)+\omega_{\mathrm{e}} L_{\mathrm{q}} i_{\mathrm{q}}(k+1)\right]+i_{\mathrm{d}}(k+1)-i_{\mathrm{d}}^{*}, \\
C_{\mathrm{q}}=\frac{T_{\mathrm{S}}}{L_{\mathrm{q}}}\left[-R i_{\mathrm{q}}(k+1)-\omega_{\mathrm{e}}\left[L_{\mathrm{d}} i_{\mathrm{d}}(k+1)+\psi_{\mathrm{f}}\right]\right]+i_{\mathrm{q}}(k+1)-i_{\mathrm{q}}^{*} .
\end{array}\right.
$$

According to Equation (6), the values of PCEs are related with the $\mathrm{d}$ - and q-axis voltages, and thus, the position of the PCE in the $e_{\mathrm{id}}-e_{\mathrm{iq}}$ coordinate system, as shown in Figure 5, are changed by selecting different VVs.

In Figure $5, e_{1}-e_{6}$ represents the PCE vector by applying the VVs $V_{1}-V_{6}$, and $\mathrm{e}_{0}$ represents the PCE vector of the zero VVs. Owing to the corresponding $\mathrm{d}$ - and q-axis voltages for the zero VVs are both 0 , the coordinate of $e_{0}$ is $\left(C_{\mathrm{d}}, C_{\mathrm{q}}\right)$ according to Equation (6). The variables of $C_{\mathrm{d}}$ and $C_{\mathrm{q}}$ are determined by the VV that applied in the current period and have no relation with the selected VV in the next period, and thus, they can be viewed as constants in Equation (6).

The reference current tracking problem can be solved by selecting appropriate VVs to make both the $e_{\mathrm{id}}$ and $e_{\mathrm{iq}}$ become zero, i.e, the current can track its reference by making the current error vector reach the coordinate origin as shown in Figure 5. In fact, the optimal VV selecting process of the conventional MPC-RCMV method can be viewed as determining the nearest PCE from the coordinate origin by minimizing the cost function. As an example, the vector $V_{1}$ will be selected for the case shown in Figure 5 with the conventional MPC-RCMV method. Owing to the fact that only single $\mathrm{VV}$ is selected during one control period for the conventional MPC-RCMV, the selected optimal VV may not ensure the current error vector reach the coordinate origin. In this part, the MPC-RCMV method with constant switching frequency is proposed by adopting four nonzero VVs in one control period to ensure the average current error approach to 0 within one period for the case shown in Figure 5.

A new coordinate system $\left(e_{\mathrm{id}}^{\prime}-e_{\mathrm{iq}}^{\prime}\right.$ as shown in Figure 5$)$ is defined by the transformation given in following equation:

$$
\left\{\begin{array}{l}
e_{\mathrm{id}}^{\prime}=e_{\mathrm{id}}-C_{\mathrm{d}}=\frac{V_{\mathrm{id}} T_{\mathrm{s}}}{L_{\mathrm{d}}} \\
e_{\mathrm{id}}^{\prime}=e_{\mathrm{iq}}-C_{\mathrm{q}}=\frac{V_{\mathrm{iq}} T_{\mathrm{s}}}{L_{\mathrm{q}}}
\end{array}\right.
$$

The reference current error vector $\left(e^{*}\right)$ is defined as the vector $\overrightarrow{O^{\prime} O}$, and its coordinate is $\left(-C_{\mathrm{d}},-C_{\mathrm{q}}\right)$. The reference current tracking problem can be solved by synthetizing $e^{*}$ with the PCE vectors $\left(e_{1}-e_{6}\right.$ as shown in Figure 5$)$.

The vector selection process can be implemented according to the angle of $e^{*}, e_{1}, e_{2}, e_{3}, e_{4}, e_{5}$, and $e_{6}$ in the $e_{\mathrm{id}}^{\prime}-e_{\mathrm{iq}}^{\prime}$ coordinate system which can be calculated by the following equation:

$$
\theta=a \tan 2\left(e_{\mathrm{id}}^{\prime}, e_{\mathrm{id}}^{\prime}\right)
$$

The sector $(S)$ is defined as shown in Figure 5 and can be obtained according to Table 1 , and then, the selected VVs can be determined. In Table 1 , the variable $\theta_{i}(i=1,2,3,4,5$, and 6$)$ and $\theta^{*}$ represent the angle of $e_{i}$ and $e^{*}$, respectively.

According to Equation (8), the current error vector will reach the position defined in Equation (10) if the voltage vector $V_{i}$ is adopted with the duty ratio $d_{i}$. Equation (10) indicates that the change of the current error vector is proportional to 


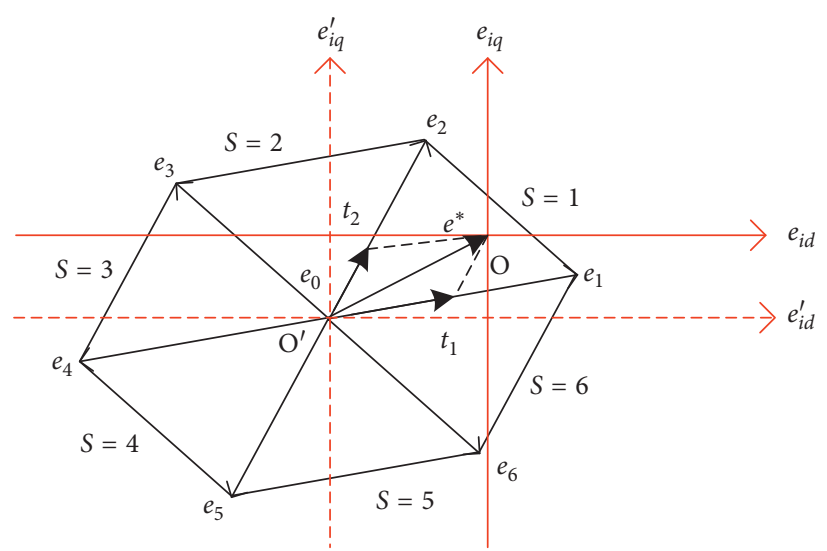

FIgURe 5: Predicted current error space vector diagram.

TABLE 1: Voltage vector selection principle.

\begin{tabular}{lll}
\hline The scope of $\theta^{*}$ & $S$ & Selected VVs \\
\hline$\theta_{1} \leq \theta^{*}<\theta_{2}$ & 1 & $V_{1}, V_{2}, V_{3}, V_{6}$ \\
$\theta_{2} \leq \theta^{*}<\theta_{3}$ & 2 & $V_{1}, V_{2}, V_{3}, V_{4}$ \\
$\theta_{3} \leq \theta^{*}<\theta_{4}$ & 3 & $V_{2}, V_{3}, V_{4}, V_{5}$ \\
$\theta_{4} \leq \theta^{*}<\theta_{5}$ & 4 & $V_{3}, V_{4}, V_{5}, V_{6}$ \\
$\theta_{5} \leq \theta^{*}<\theta_{6}$ & 5 & $V_{1}, V_{4}, V_{5}, V_{6}$ \\
$\theta_{6} \leq \theta^{*}<\theta_{1}$ & 6 & $V_{1}, V_{2}, V_{5}, V_{6}$ \\
\hline
\end{tabular}

the duty ratio of the adopted VV. Accordingly, the reference current tracking can be realized by synthetizing $e^{*}$ with linear combination of the PCE vector of the selected VVs.

$$
\left\{\begin{array}{l}
e_{\mathrm{id}}^{\prime}=\frac{V_{\mathrm{id}}}{L_{\mathrm{d}}} d_{i} T_{\mathrm{s}}, \\
e_{\mathrm{id}}^{\prime}=\frac{V_{\mathrm{iq}}}{L_{\mathrm{q}}} d_{i} T_{\mathrm{s}} .
\end{array}\right.
$$

According to the nearest three-vector principle, $e^{*}$ can be synthetized by $e_{0}, e_{1}$, and $e_{2}$ for the case that $S$ is 1 as shown in Figure 5. Owing to that the zero vectors should be avoided to restrict the CMV amplitude, two opposing PCEs $\left(e_{3}\right.$ and $\left.e_{6}\right)$ with equal duty cycle can be utilized to create equivalent $e_{0}$. The duty ratios of the adopted VVs can be calculated by Equation (11) if $S$ is 1 .

$$
\left\{\begin{array}{l}
V_{1 \mathrm{~d}} d_{1}+V_{2 \mathrm{~d}} d_{2}=-\frac{C_{\mathrm{d}} L_{\mathrm{d}}}{T_{\mathrm{s}}} \\
V_{1 \mathrm{q}} d_{1}+V_{2 \mathrm{~d}} d_{2}=-\frac{C_{\mathrm{q}} L_{\mathrm{q}}}{T_{\mathrm{s}}} \\
d_{3}=d_{6}=\frac{\left(1-d_{1}-d_{2}\right)}{2}
\end{array}\right.
$$

However, the duty ratios calculated by Equation (11) needs to be adjusted as Equation (12) for the case where the reference current error vector $\left(e^{*}\right)$ is outside of the hexagon enclosed by $e_{1}-e_{6}$ as shown in Figure 6 .

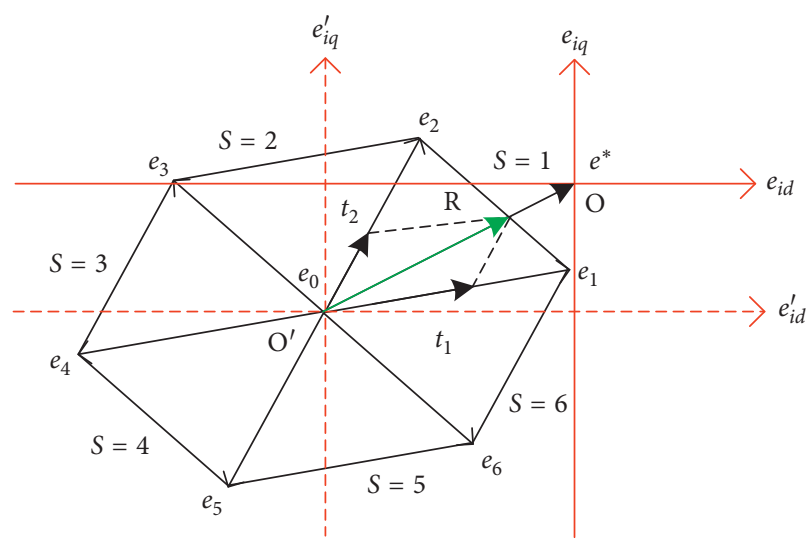

Figure 6: Predicted current error space vector diagram.

TABLe 2: Switching sequence design.

\begin{tabular}{lc}
\hline$S$ & Switching sequence \\
\hline 1 & $V_{3}-V_{2}-V_{1}-V_{6}-V_{1}-V_{2}-V_{3}$ \\
2 & $V_{4}-V_{3}-V_{2}-V_{1}-V_{2}-V_{3}-V_{4}$ \\
3 & $V_{5}-V_{4}-V_{3}-V_{2}-V_{3}-V_{4}-V_{5}$ \\
4 & $V_{6}-V_{5}-V_{4}-V_{3}-V_{4}-V_{5}-V_{6}$ \\
5 & $V_{1}-V_{6}-V_{5}-V_{4}-V_{5}-V_{6}-V_{1}$ \\
6 & $V_{2}-V_{1}-V_{6}-V_{5}-V_{6}-V_{1}-V_{2}$ \\
\hline
\end{tabular}

$$
\left\{\begin{array}{l}
d_{1}^{\prime}=\frac{d_{1}}{d_{1}+d_{2}} \\
d_{2}^{\prime}=\frac{d_{2}}{d_{1}+d_{2}} \\
d_{3}^{\prime}=d_{6}^{\prime}=0
\end{array}\right.
$$

If $e^{*}$ locates in other sectors, the duty ratio calculating method is the same as the case where $S$ is 1 . After obtaining the duty ratios of the adopted VVs, the switching sequence can be designed as shown in Table 2 .

The flowchart of the proposed method is shown in Figure $7(\mathrm{~b})$. The values of $i_{\mathrm{q}}(k+1)$ and $i_{\mathrm{d}}(k+1)$ are firstly calculated by Equation (4), and then, $e_{\mathrm{id}}$ and $e_{\mathrm{iq}}$ for different 


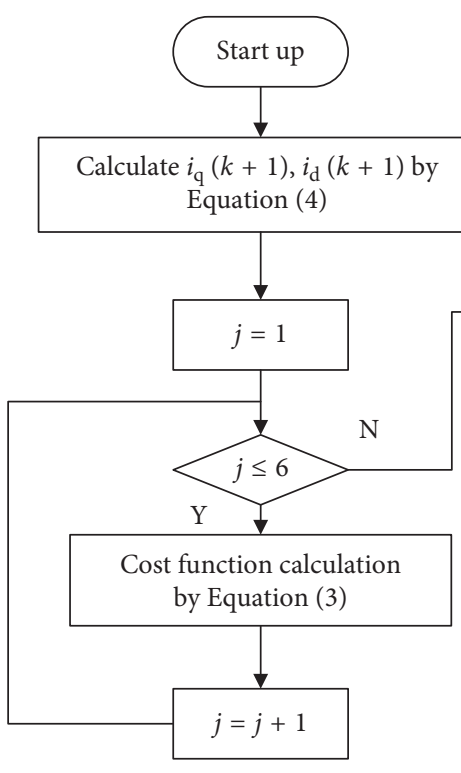

(a)

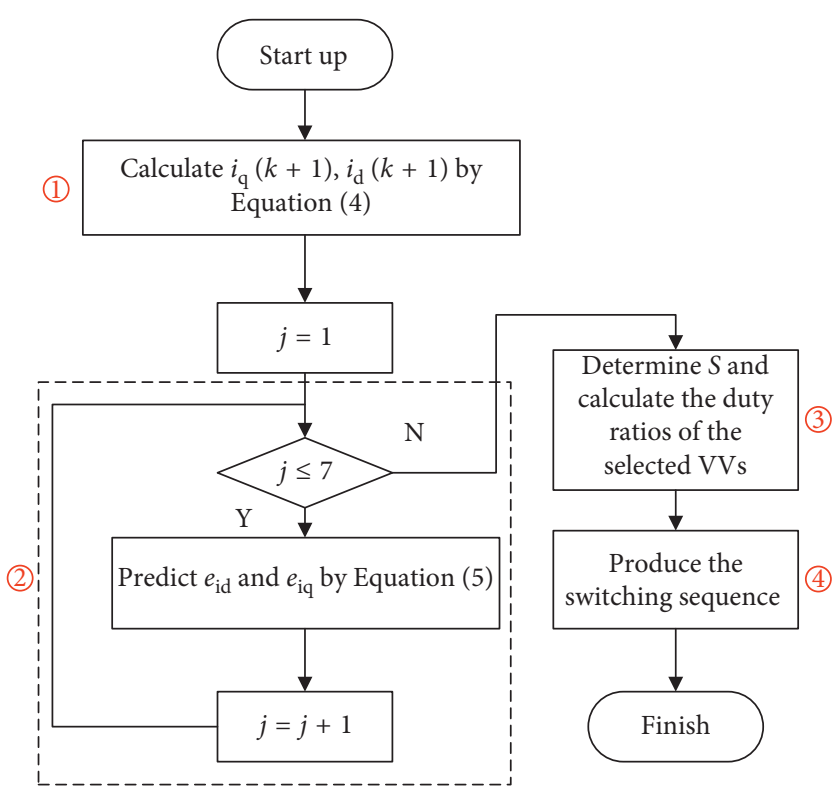

(b)

FIgURE 7: Flowchart of the conventional and proposed method. (a) The conventional method. (b) The proposed method.

active VVs can be obtained by Equation (5). The sector and the selected VVs can be determined by Table 1 and the duty ratios of the selected VVs can be calculated by Equations (11) and (12). Finally, the switching sequence can be obtained according to Table 2.

\section{Simulation and Experimental Validation}

4.1. Simulation Results and Analysis. To validate the effectiveness of the proposed MPC-RCMV with constant switching frequency, the strategy is simulated by Matlab/Simulink and the main parameters are given in Table 3.

To minimize the copper losses of the PMSM, the maximal torque per ampere (MTPA) strategy [31, 32] is adopted and the reference of the $\mathrm{d}$ - and q-axis current can be calculated as Equation (13) where $i_{\mathrm{s}}^{*}$ is the reference of the stator current.

$$
\left\{\begin{array}{l}
i_{\mathrm{d}}^{*}=\frac{\psi_{\mathrm{f}}}{4\left(L_{\mathrm{q}}-L_{\mathrm{d}}\right)}-\sqrt{\frac{\psi_{\mathrm{f}}}{16\left(L_{\mathrm{q}}-L_{\mathrm{d}}\right)^{2}}+\frac{\left|i_{\mathrm{s}}^{*}\right|^{2}}{2}} \\
i_{\mathrm{q}}^{*}=\operatorname{sign}\left(i_{\mathrm{s}}^{*}\right) \sqrt{i_{\mathrm{s}}^{* 2}-i_{\mathrm{d}}^{* 2}}
\end{array}\right.
$$

In the simulation, $i_{s}^{*}$ is set as $200 \mathrm{~A}$ and $300 \mathrm{~A}$ at the interval $0-0.5 \mathrm{~s}$ and $0.5-1 \mathrm{~s}$, respectively. The speed of the motor is set as $750 \mathrm{r} / \mathrm{min}$ in the simulation.

The line-to-line voltage $\left(V_{\mathrm{ab}}\right), \mathrm{CMV}$, and three-phase current waveforms for both the conventional $6 \mathrm{VV}$ strategy, and the proposed method are given in Figure 8. The CMV curves in Figure 8 indicate that the amplitude of the CMV has been restricted within sixth of the dc-link voltage with both the conventional and the proposed methods.
TABle 3: Main parameters of the simulation.

\begin{tabular}{lc}
\hline Parameters & Values \\
\hline Flux linkage & $0.225 \mathrm{~Wb}$ \\
D-axis inductor & $0.95 \mathrm{mH}$ \\
Q-axis inductor & $2.05 \mathrm{mH}$ \\
Resistance & $0.1 \Omega$ \\
Pole pairs & 4 \\
Sampling time & $100 \mu \mathrm{s}$ \\
\hline
\end{tabular}

The waveforms of the $\mathrm{d}$ - and q-axis current and the electromagnetic torque $\left(T_{\mathrm{e}}\right)$ for both the conventional and the proposed methods are shown in Figure 9. It can be seen from Figure 9 that the fluctuations of $i_{\mathrm{d}}, i_{\mathrm{q}}$, and $T_{\mathrm{e}}$ of the proposed method are far smaller than the conventional method. The comparison results of the peak-to-peak of the fluctuation of $i_{\mathrm{d}}, i_{\mathrm{q}}$, and $T_{\mathrm{e}}$ are given in Table 4 . In the case where $T_{s}$ of these two methods are both set as $100 \mu \mathrm{s}$, the fluctuations of $i_{\mathrm{d}}, i_{\mathrm{q}}$, and $T_{\mathrm{e}}$ with the proposed method in the case where $i_{\mathrm{s}}^{*}$ is set $200 \mathrm{~A}$ reduce by $95.9 \%, 97.8 \%$, and $78.2 \%$, respectively. In addition, the fluctuations of $i_{\mathrm{d}}, i_{\mathrm{q}}$, and $T_{\mathrm{e}}$ in the case where $i_{\mathrm{s}}^{*}$ is set $300 \mathrm{~A}$ reduce by $95.9 \%, 98.2 \%$, and $74.8 \%$, respectively. In Table 4 , the peak-to-peak of the fluctuation of $i_{\mathrm{d}}, i_{\mathrm{q}}$, and $T_{\mathrm{e}}$ for the conventional method with $T_{\mathrm{s}}$ set as $50 \mu \mathrm{s}$ is also analyzed, and the fluctuations of $i_{\mathrm{d}}, i_{\mathrm{q}}$, and $T_{\mathrm{e}}$ are still much bigger than the proposed method with $T_{\mathrm{s}}$ set as $100 \mu \mathrm{s}$, which indicate that the control performance of the proposed method is greatly enhanced compared with the conventional method.

The fast Fourier transform analysis results of the phase current for both the conventional and the proposed methods are shown in Figure 10. The results in Figure 10 indicate that the main current harmonics components of the proposed method concentrate on the switching frequency $(10 \mathrm{kHz})$ 

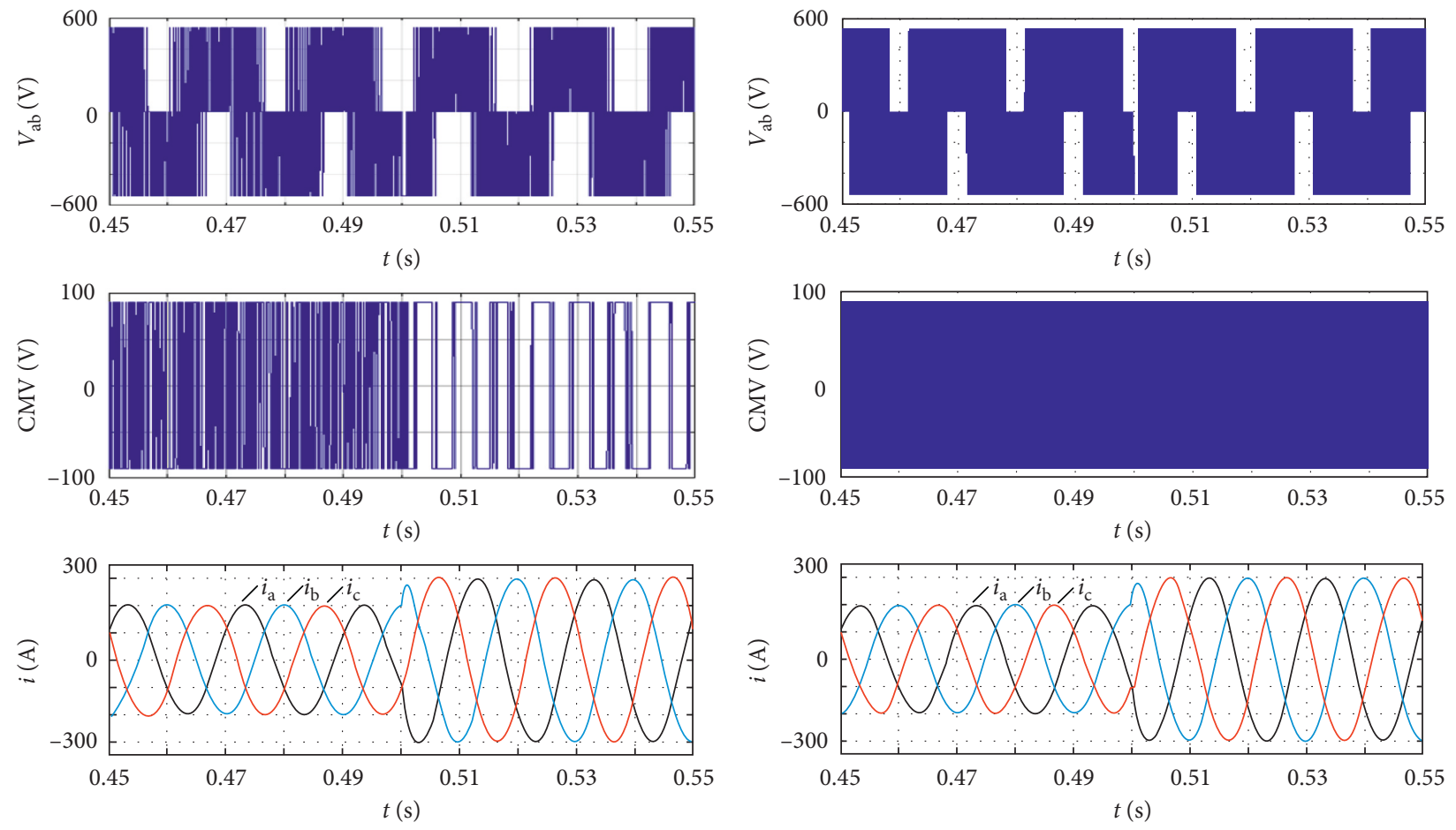

(a)

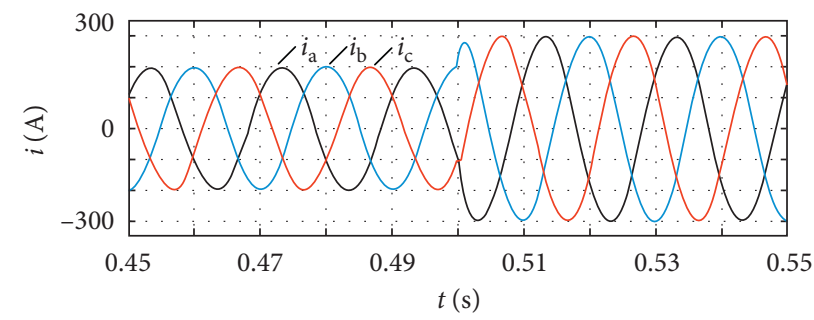

(b)

FIGURE 8: The line-to-line voltage $\left(V_{\mathrm{ab}}\right)$, the common-mode voltage, and three-phase current waveforms. (a) The conventional MPCRCMV. (b) The proposed MPC-RCMV with constant switching frequency.
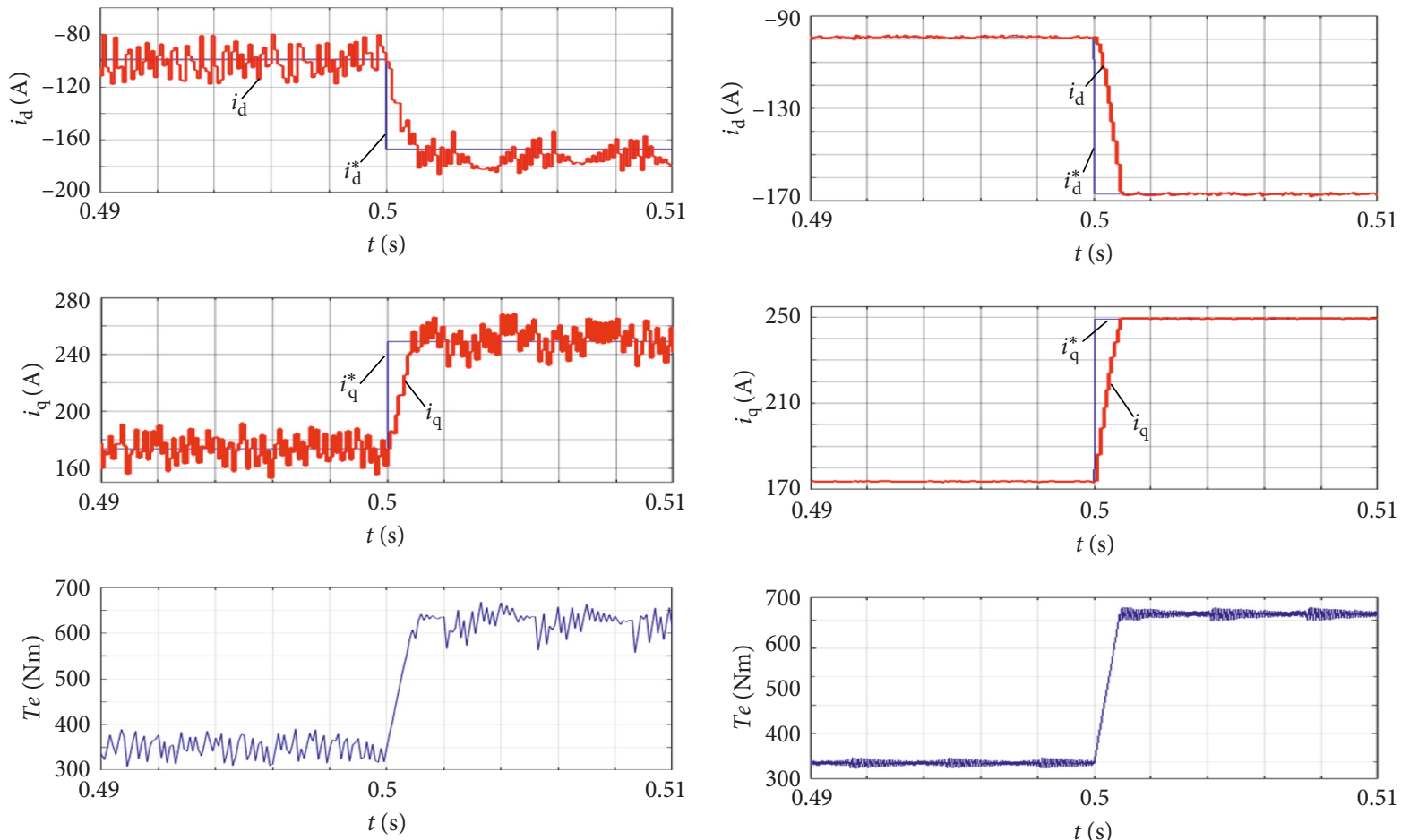

(a)

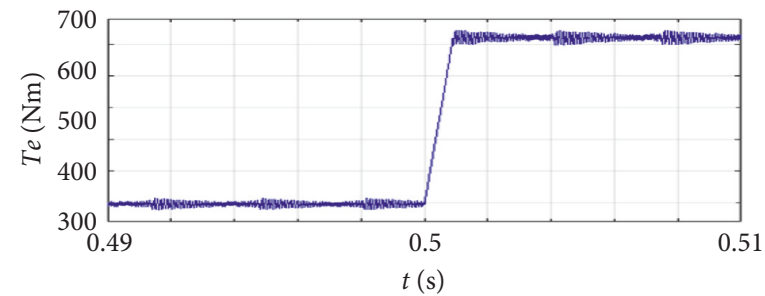

(b)

FIGURE 9: d- and q-axis current and the electromagnetic torque waveforms. (a) The conventional MPC-RCMV. (b) The proposed MPCRCMV with constant switching frequency. 
TABLE 4: Comparison results of the peak-to-peak of the fluctuation of $i_{\mathrm{d}}, i_{\mathrm{q}}$, and $T_{\mathrm{e}}$.

Peak-to-peak

of the The conventional method $\left(T_{\mathrm{s}}=100 \mu \mathrm{s}\right) \quad$ The conventional method $\left(T_{\mathrm{s}}=50 \mu \mathrm{s}\right) \quad$ The proposed method $\left(T_{\mathrm{s}}=100 \mu \mathrm{s}\right)$ fluctuation

\begin{tabular}{|c|c|c|c|c|}
\hline & $i_{\mathrm{s}}^{*}=200 \mathrm{~A}$ & $36.5 \mathrm{~A}$ & $18.2 \mathrm{~A}$ & $1.5 \mathrm{~A}$ \\
\hline$i_{\mathrm{d}}$ & $i_{\mathrm{s}}^{*}=300 \mathrm{~A}$ & $34.3 \mathrm{~A}$ & $18.1 \mathrm{~A}$ & $1.4 \mathrm{~A}$ \\
\hline & $i_{\mathrm{s}}^{*}=200 \mathrm{~A}$ & $40.5 \mathrm{~A}$ & $19.8 \mathrm{~A}$ & $0.9 \mathrm{~A}$ \\
\hline$i_{\mathrm{q}}$ & $i_{\mathrm{s}}^{*}=300 \mathrm{~A}$ & $33.3 \mathrm{~A}$ & $17.9 \mathrm{~A}$ & $0.6 \mathrm{~A}$ \\
\hline & $i_{\mathrm{s}}^{*}=200 \mathrm{~A}$ & $91.5 \mathrm{Nm}$ & $45.6 \mathrm{Nm}$ & $19.9 \mathrm{Nm}$ \\
\hline$T_{\mathrm{e}}$ & $i_{\mathrm{s}}^{*}=300 \mathrm{~A}$ & $97.8 \mathrm{Nm}$ & $50.1 \mathrm{Nm}$ & $24.6 \mathrm{Nm}$ \\
\hline
\end{tabular}

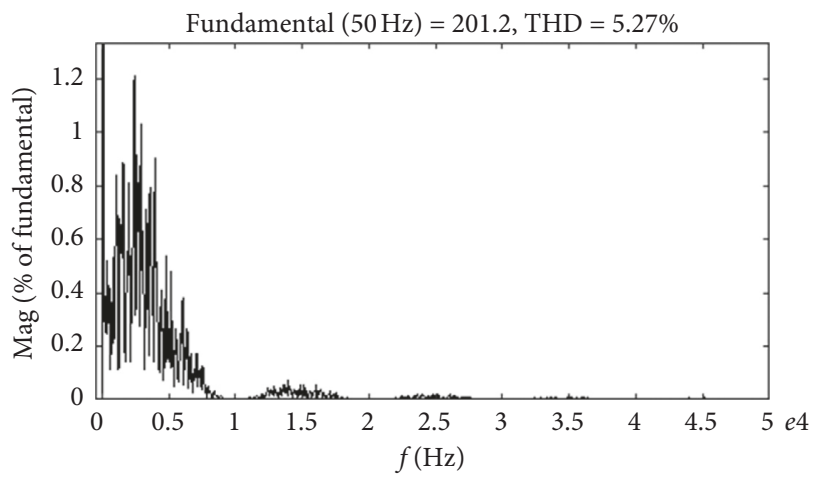

(a)

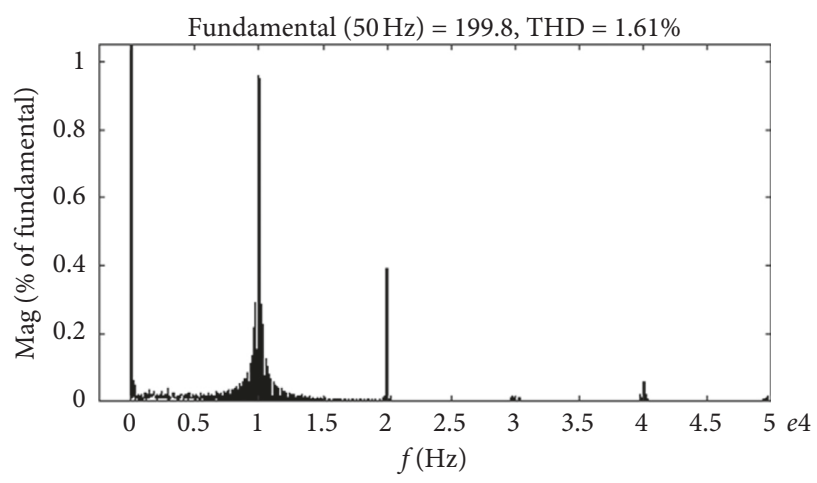

(c)

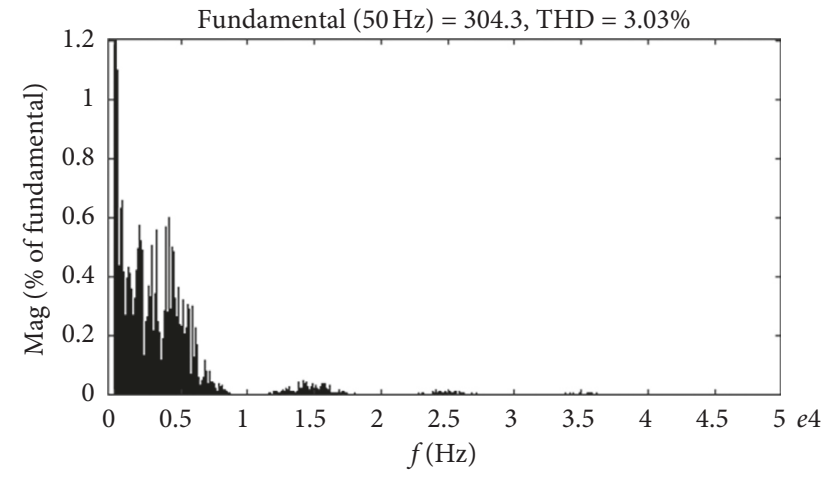

(b)

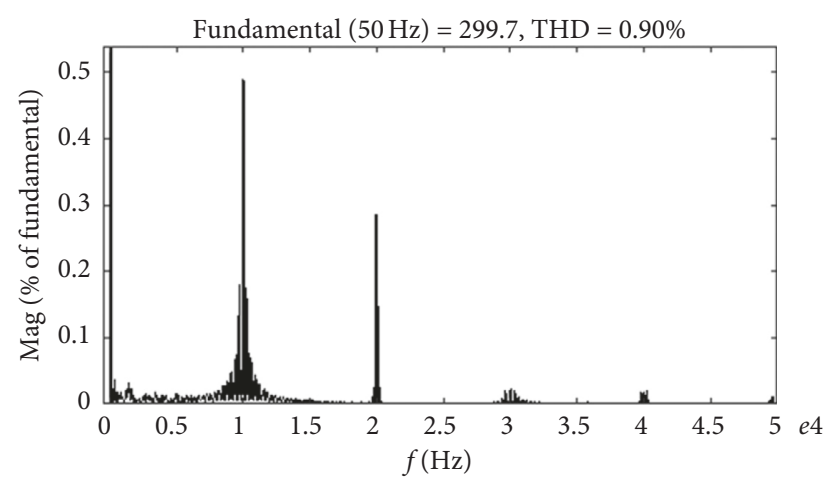

(d)

Figure 10: The fast Fourier transform analysis of the phase current. (a) The conventional MPC-RCMV $\left(i_{\mathrm{s}}^{*}=200 \mathrm{~A}\right.$ ). (b) The conventional MPC-RCMV $\left(i_{s}^{*}=300 \mathrm{~A}\right)$. (c) The proposed MPC-RCMV $\left(i_{s}^{*}=200 \mathrm{~A}\right)$. (d) The proposed MPC-RCMV $\left(i_{\mathrm{s}}^{*}=300 \mathrm{~A}\right)$.

and its multiple, which is helpful for the harmonic filter design. In addition, the total harmonic distortion (THD) of the phase current with the proposed method is smaller than the conventional one.

Accordingly, it can be concluded that the proposed MPC-RCMV with constant switching frequency shows great advantages over the conventional $6 \mathrm{VV}$ strategy, mainly in the current and torque ripple reduction.

In order to illustrate the advantage of the proposed method over the MPC controller without considering the target of CMV reduction, the comparison results between the MPC method with constant switching frequency in [27] and the proposed method are shown in Figure 11. In Figure 11, the MPC method in [27] is adopted before $0.2 \mathrm{~s}$ and the proposed method is used after $0.2 \mathrm{~s}$. The line-to-line voltage, CMV, and three-phase currents are shown in Figure 11. The CMV amplitude of the MPC method in [27] reaches to the half of the dc-link voltage, but it has been limited within sixth of the dc-link voltage with the proposed method. Accordingly, the main advantage of the proposed method is that the CMV can be reduced.

4.2. Experimental Validation. To validate the effectiveness of the proposed MPC-RCMV with constant switching frequency, an experimental prototype has been established as shown in Figure 12. A $540 \mathrm{~V}$ dc-link voltage is obtained by the PWM rectifier. The motor 1 is connected with the inverter 1, and the proposed MPC-RCMV with constant switching frequency is implemented by the controller 1 . The 

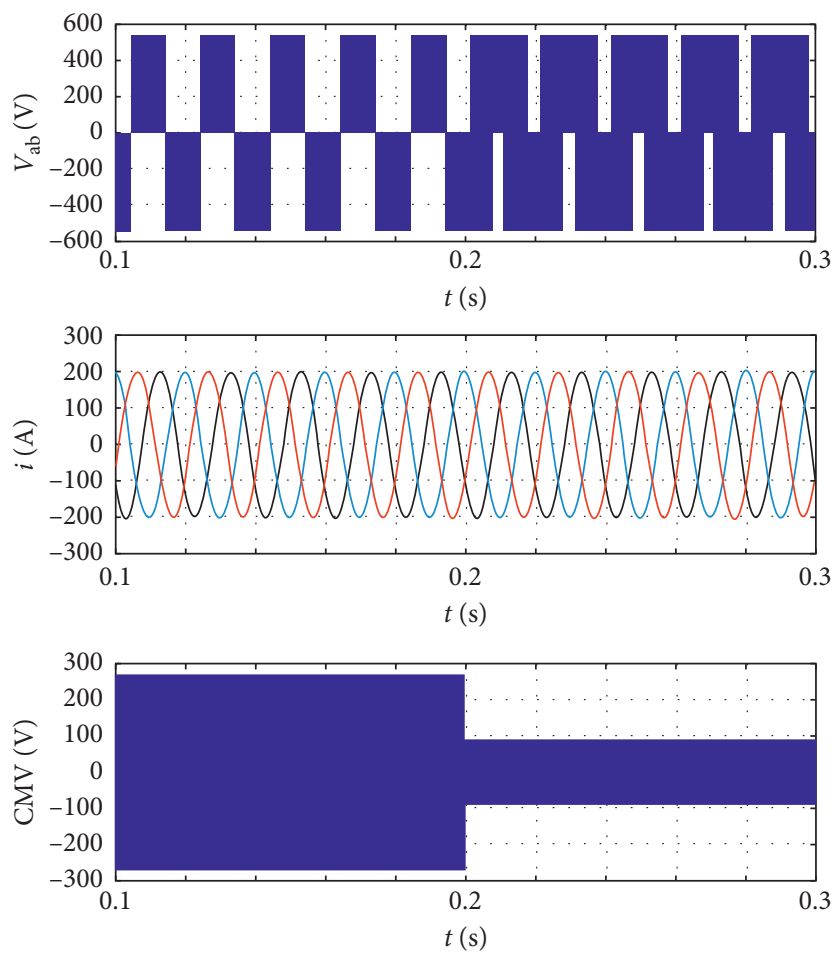

FIGURE 11: Comparison results between the MPC method with constant switching frequency in [27] and the proposed method.
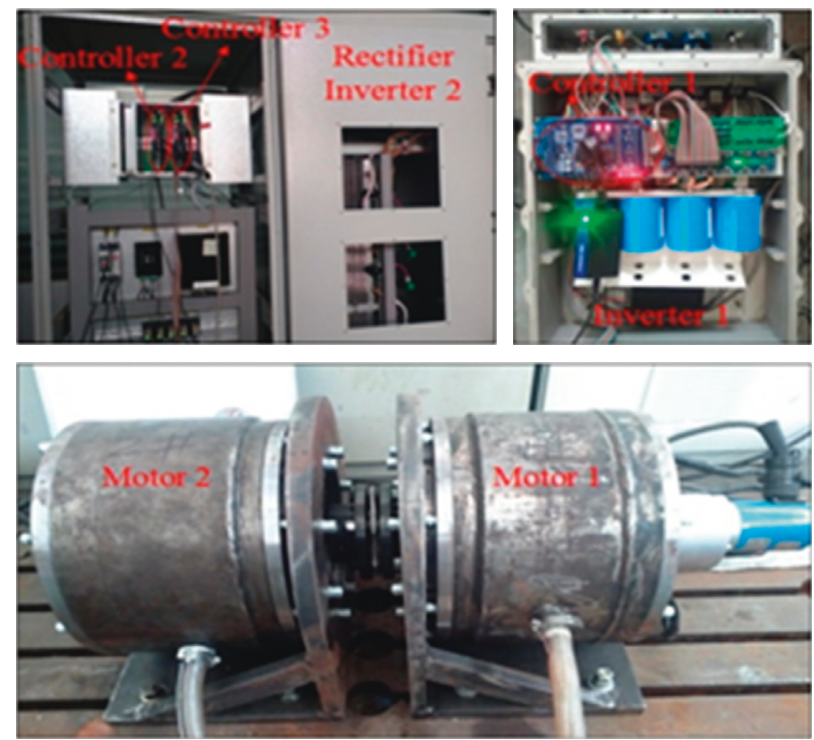

FIgURE 12: The experimental prototype.

motor 2 is a load motor which is controlled by the inverter 2 . The parameters of the PMSM are the same as the simulation.

In the experiment, a 150-MIPS fixed-point 32-bit TMS320F2812 DSP board is adopted to carry out the computation. The execution time for the proposed MPC-RCMV methods with necessary protecting and sampling process is $83 \mu \mathrm{s}$. To introduce the real-time implementation details, the flowchart of the proposed method in Figure $7(\mathrm{~b})$ is divided into 4 parts, and the execution time of these four parts are $5 \mu \mathrm{s}$, $61 \mu \mathrm{s}, 6 \mu \mathrm{s}$, and $2 \mu \mathrm{s}$, respectively. The other execution time is for the necessary sampling and protecting process.
The d- and q-axis current waveforms for the both conventional and proposed methods, which are measured through a digital-to-analog (DA) chip (TLV5610) on the control board, are shown in Figure 13, where the reference stator current changes from $100 \mathrm{~A}$ to $150 \mathrm{~A}$ at the middle of the graph. The results in Figure 13(b) indicate that the d-and q-axis current reference can be fast tracked with high precision as the conventional method as shown in Figure 13(a). In addition, it can be seen from Figure 13 that the ripples of both the $\mathrm{d}$ - and q-axis current for the proposed method have been greatly reduced compared with the conventional one. 


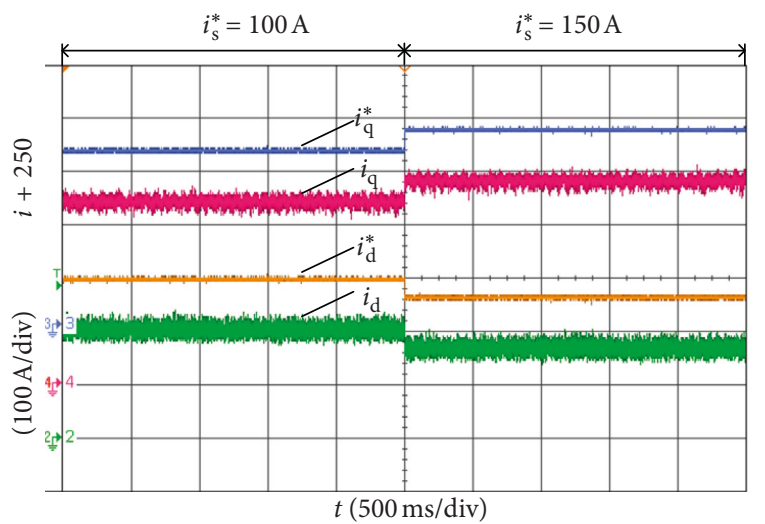

(a)

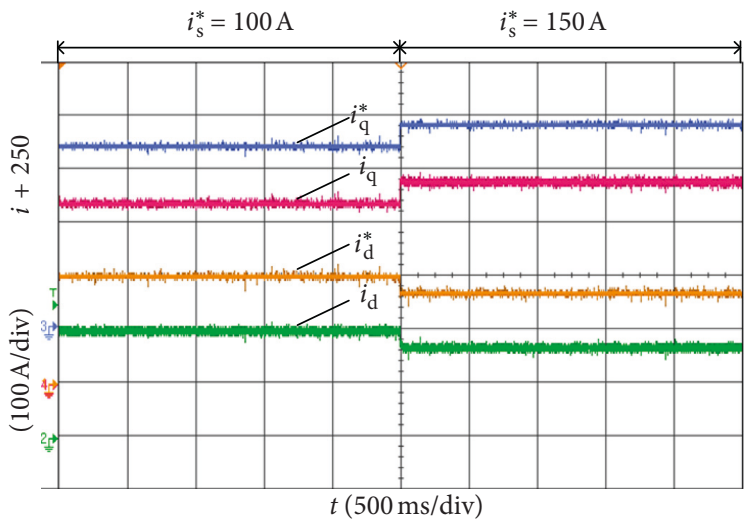

(b)

FIGURE 13: d- and q-axis current waveforms. (a) The conventional MPC-RCMV. (b) The proposed MPC-RCMV with constant switching frequency.

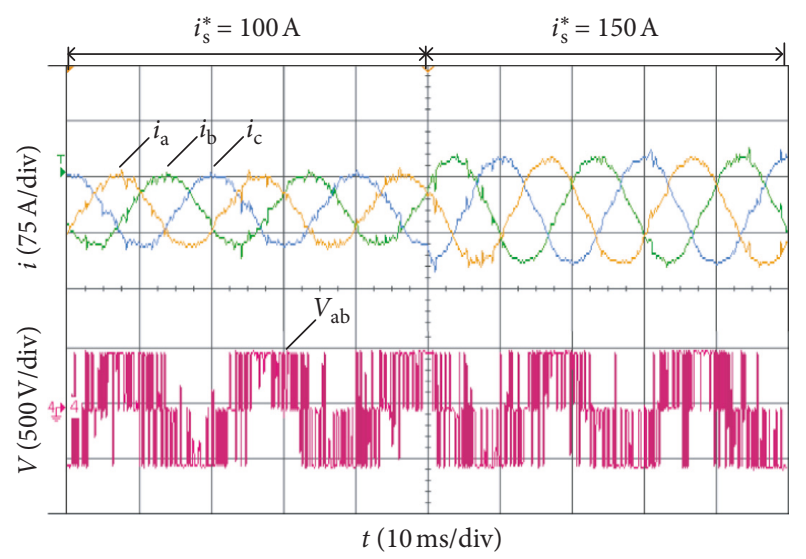

(a)

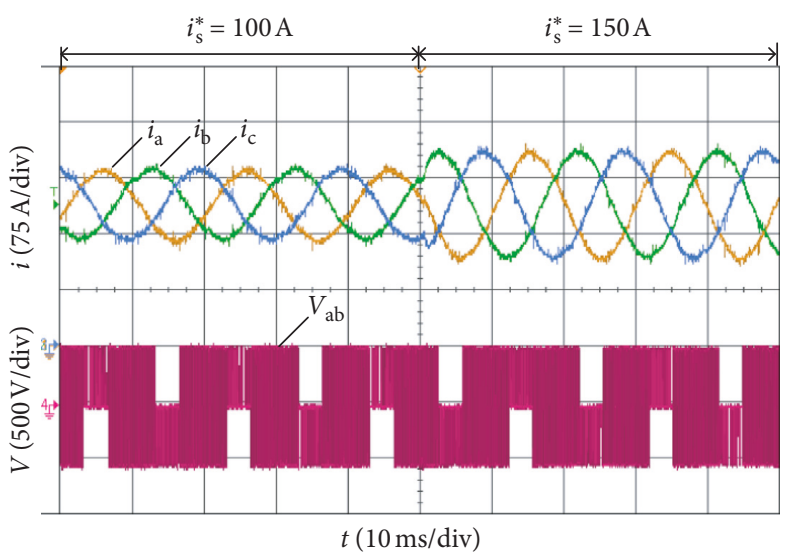

(b)

FIgure 14: Three-phase current and line-to-line voltage curves. (a) The conventional MPC-RCMV. (b) The proposed MPC-RCMV with constant switching frequency.

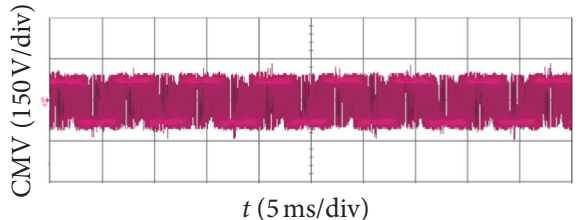

(a)

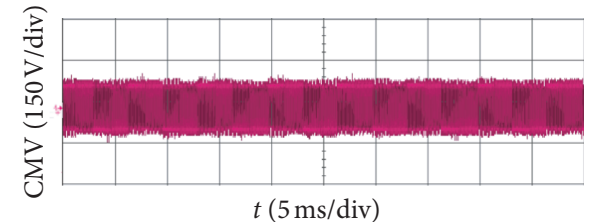

(b)

Figure 15: CMV curves. (a) The conventional MPC-RCMV. (b) The proposed MPC-RCMV with constant switching frequency.

The three-phase currents and the line-to-line voltage curves for the both methods are shown in Figure 14. The THD values for the conventional method where the reference of the stator current is $100 \mathrm{~A}$ and $150 \mathrm{~A}$ are $6.3 \%$ and $5.1 \%$, respectively. The THD values for the proposed method where the reference of the stator current is $100 \mathrm{~A}$ and $150 \mathrm{~A}$ are $2.4 \%$ and $1.6 \%$, respectively. Thus, the current quality of the proposed method has been greatly improved. The CMV curves shown in Figure 15 indicate that the amplitude of the
CMV has been successfully restricted within sixth of the dclink voltage. Accordingly, the effectiveness of the proposed method has been verified by the experimental results.

\section{Conclusion}

A MPC-RCMV method with constant switching frequency for the PMSM drives is studied in detail. In the proposed method, four nonzero VVs are adopted and the switching 
sequence is designed according to the established current predictive error space vector diagram. Unlike the conventional methods where the switching frequency changes with the work condition of PMSM, the average switching frequency is fixed and equal to $1 / T_{s}$. The simulation and experiment results indicate that the current reference can be fast and accurately tracked, and the current ripples are greatly reduced.

\section{Data Availability}

The data used to support the findings of this study are available from the corresponding author upon request.

\section{Conflicts of Interest}

The authors declare that there are no conflicts of interest regarding the publication of this paper.

\section{Acknowledgments}

This paper is partly funded by the National Natural Science Foundation of China under Award U1610113 and National key Research and Development Project of China under award 2016YFC0600804.

\section{References}

[1] H. Chen and H. Zhao, "Review on pulse-width modulation strategies for common-mode voltage reduction in three-phase voltage-source inverters," IET Power Electronics, vol. 9, no. 14, pp. 2611-2620, 2016.

[2] H. Cao, "A novel power electronic inverter circuit for transformerless photovoltaic systems," Active \& Passive Electronic Components, vol. 2014, Article ID 329043, 5 pages, 2014.

[3] M. Asefi and J. Nazarzadeh, "Survey on high-frequency models of PWM electric drives for shaft voltage and bearing current analysis," IET Electrical Systems in Transportation, vol. 7, no. 3, pp. 179-189, 2017.

[4] N. Mousavi, T. Rahimi, and H. M. Kelk, "Reduction EMI of BLDC motor drive based on software analysis," Advances in Materials Science and Engineering, vol. 2016, Article ID 1497360, 9 pages, 2016.

[5] K. S. Narayana, A. K. Rao, and K. Satyanarayana, "Novel AZSPWM algorithms based VCIMD for reduced CMV variations," International Journal of Power Electronics and Drive Systems (IJPEDS), vol. 3, no. 1, pp. 1-8, 2013.

[6] E. Un and A. M. Hava, "A near state PWM method with reduced switching frequency and reduced common mode voltage for three-phase voltage source inverters," IEEE Transactions on Industry Applications, vol. 45, no. 2, pp. 782-793, 2009.

[7] A. M. Hava and E. Un, "Performance analysis of reduced common-mode voltage PWM methods and comparison with standard PWM methods for three-phase voltage-source inverters," IEEE Transactions on Power Electronics, vol. 24, no. 1, pp. 241-252, 2009.

[8] X. Wu, G. Tan, Z. Ye, Y. Liu, and S. Xu, "Optimized commonmode voltage reduction PWM for three-phase voltage-source inverters," IEEE Transactions on Power Electronics, vol. 31, no. 4, pp. 2959-2969, 2016.
[9] P. Chaturvedi, S. Jain, and P. Agarwal, "Carrier-based common mode voltage control techniques in three-level diodeclamped inverter," Advances in Power Electronics, vol. 2012, Article ID 327157, 13 pages, 2012.

[10] R. Wang, X. Mu, Z. Wu, L. Zhu, and Z. Chen, "Carrier-based PWM method to reduce common-mode voltage of three-tofive-phase indirect matrix converter," Mathematical Problems in Engineering, vol. 2016, Article ID 6086497, 12 pages, 2016.

[11] J. Huang, Q. Liu, X. Wang, and K. Li, "A carrier-based modulation scheme to reduce the third harmonic component of common-mode voltage in a three-phase inverter under high DC voltage utilization," IEEE Transactions on Industrial Electronics, vol. 65, no. 3, pp. 1931-1940, 2018.

[12] J. Huang and H. Shi, "Suppressing low-frequency components of common-mode voltage through reverse injection in threephase inverter," IET Power Electronics, vol. 7, no. 6, pp. 1644-1653, 2014.

[13] K. Tian, J. Wang, B. Wu, Z. Cheng, and N. R. Zargari, "A virtual space vector modulation technique for the reduction of common-mode voltages in both magnitude and third-order component," IEEE Transactions on Power Electronics, vol. 31, no. 1, pp. 839-848, 2016.

[14] X. Wu, H. Liu, X. Yuan, S. Huang, and D. Luo, "Design and implementation of recursive model predictive control for permanent magnet synchronous motor drives," Mathematical Problems in Engineering, vol. 2015, Article ID 431734, 11 pages, 2015.

[15] S. Zhang, H. Cao, Y. Zhang, L. Jia, and Z. Ye, "Data-driven optimization framework for nonlinear model predictive control," Mathematical Problems in Engineering, vol. 2017, Article ID 9402684, 15 pages, 2017.

[16] S. K. Hoseini, J. Adabi, and A. Sheikholeslami, "Predictive modulation schemes to reduce common-mode voltage in three-phase inverters-fed AC drive systems," IET Power Electronics, vol. 7, no. 4, pp. 840-849, 2014.

[17] M. Preindl, E. Schaltz, and P. Thøgersen, "Switching frequency reduction using model predictive direct current control for high-power voltage source inverters," IEEE Transactions on Industrial Electronics, vol. 58, no. 7, pp. 2826-2835, 2011.

[18] L. Guo, X. Zhang, S. Yang, Z. Xie, and R. Cao, "A model predictive control-based common-mode voltage suppression strategy for voltage-source inverter," IEEE Transactions on Industrial Electronics, vol. 63, no. 10, pp. 6115-6125, 2016.

[19] S. Kwak and S. Mun, "Common-mode voltage mitigation with a predictive control method considering dead time effects of three-phase voltage source inverters," IET Power Electronics, vol. 8, no. 9, pp. 1690-1700, 2014.

[20] S. Mun and S. Kwak, "Reducing common-mode voltage of three-phase VSIs using the predictive current control method based on reference voltage," Journal of Power Electronics, vol. 15, no. 3, pp. 712-720, 2015.

[21] S. Kwak and S. Mun, "Model predictive control methods to reduce common-mode voltage for three-phase voltage source inverters," IEEE Transactions on Power Electronics, vol. 30, no. 9, pp. 5019-5035, 2015.

[22] X. Cong, H. Zhang, F. Cheng, and H. Zhang, "Model predictive control method to reduce common-mode voltage for permanent-magnet synchronous machine drives," in Proceedings of 2017 IEEE Transportation Electrification Conference and Expo, Asia-Pacific (ITEC Asia-Pacific), pp. 1-6, Harbin, China, August 2017.

[23] L. Zhang and M. Dou, "Multiprotocol communication interface pmsm control on account of industrial configuration 
software," Journal of Electrical and Computer Engineering, vol. 2014, Article ID 651216, 6 pages, 2014.

[24] F. Khammar and N. Debbache, "Application of artificial intelligence techniques for the control of the asynchronous machine," Journal of Electrical and Computer Engineering, vol. 2016, Article ID 8052027, 11 pages, 2016.

[25] M. Tomlinson, H. D. T. Mouton, R. Kennel, and P. Stolze, "A fixed switching frequency scheme for finite-control-set model predictive control-concept and algorithm," IEEE Transactions on Industrial Electronics, vol. 63, no. 12, pp. 7662-7670, 2016.

[26] F. Donoso, A. Mora, R. Cardenas, A. Angulo, D. Saez, and M. Rivera, "Finite-set model predictive control strategies for a 3L-NPC inverter operating with fixed switching frequency," IEEE Transactions on Industrial Electronics, vol. 65, no. 5, pp. 3954-3965, 2018.

[27] E. Fuentes, C. A. Silva, and R. M. Kennel, "MPC implementation of a quasi-time-optimal speed control for a PMSM drive, with inner modulated-FS-MPC torque control," IEEE Transactions on Industrial Electronics, vol. 63, no. 6, pp. 3897-3905, 2016.

[28] C. F. Garcia, C. A. Silva, J. R. Rodriguez, P. Zanchetta, and S. A. Odhano, "Modulated model predictive control with optimized overmodulation," IEEE Journal of Emerging and Selected Topics in Power Electronics, p. 1, 2018.

[29] J. Rodriguez and P. Cortes, Predictive Control of Power Converters and Electrical Drives, Wiley-IEEE, Hoboken, NJ, USA, 2012.

[30] H. T. Moon, H. S. Kim, and M. J. Youn, "A discrete-time predictive current control for PMSM," IEEE Transactions on Power Electronics, vol. 18, no. 1, pp. 464-472, 2003.

[31] Y. Yang, C. Da, X. Zheng, Z. Mi, X. Li, and C. Sun, "Adaptive backstepping based MTPA sensorless control of PM-assisted SynRM with fully uncertain parameters," Mathematical Problems in Engineering, vol. 2018, Article ID 8405847, 14 pages, 2018.

[32] A. Ahmed, Y. Sozer, and M. Hamdan, "Maximum torque per ampere control for buried magnet PMSM based on DC-link power measurement," IEEE Transactions on Power Electronics, vol. 32, no. 2, pp. 1299-1311, 2016. 


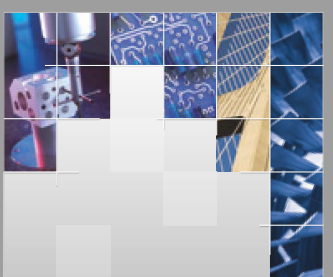

\section{Enfincering}
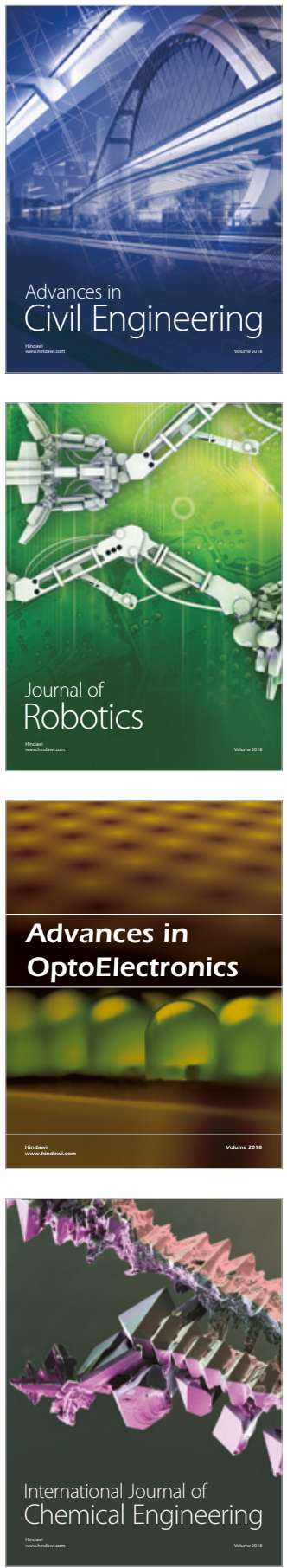

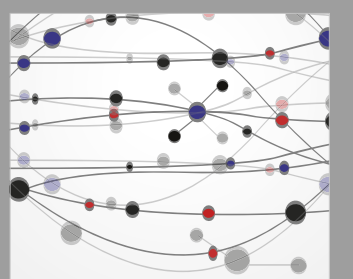

\section{Rotating \\ Machinery}

The Scientific World Journal

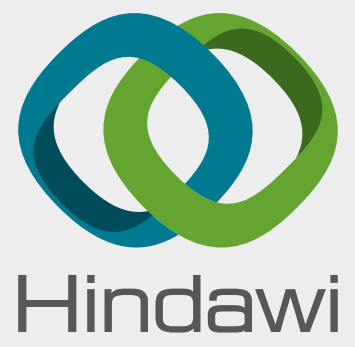

Submit your manuscripts at

www.hindawi.com
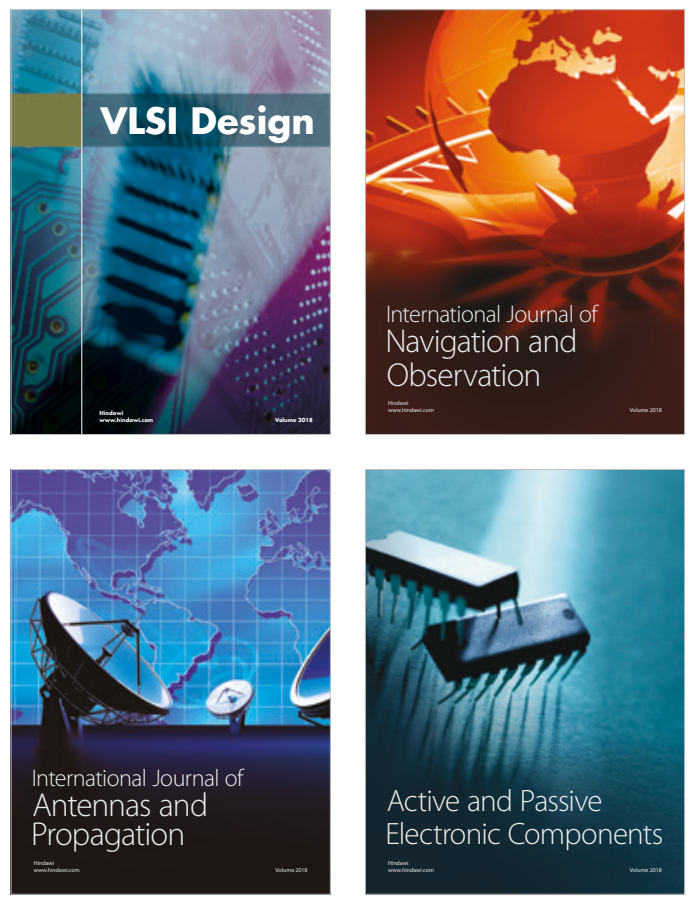
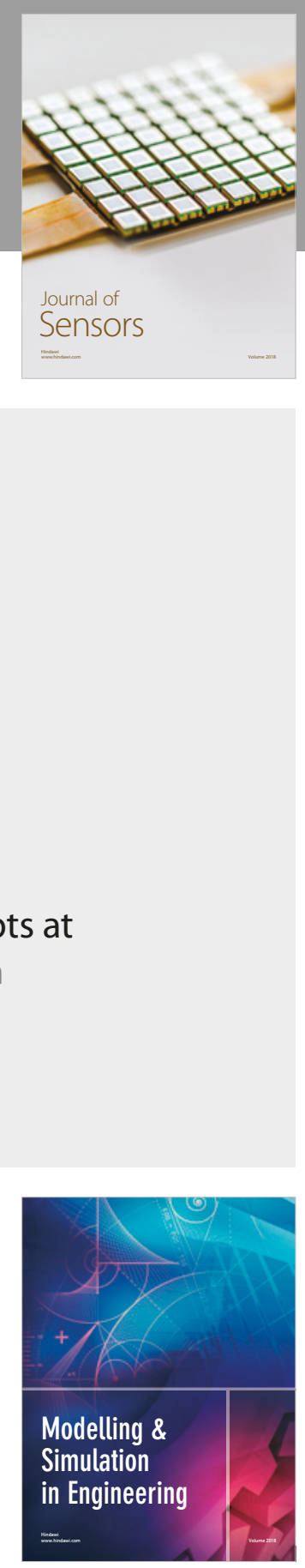

\section{Advances \\ Multimedia}
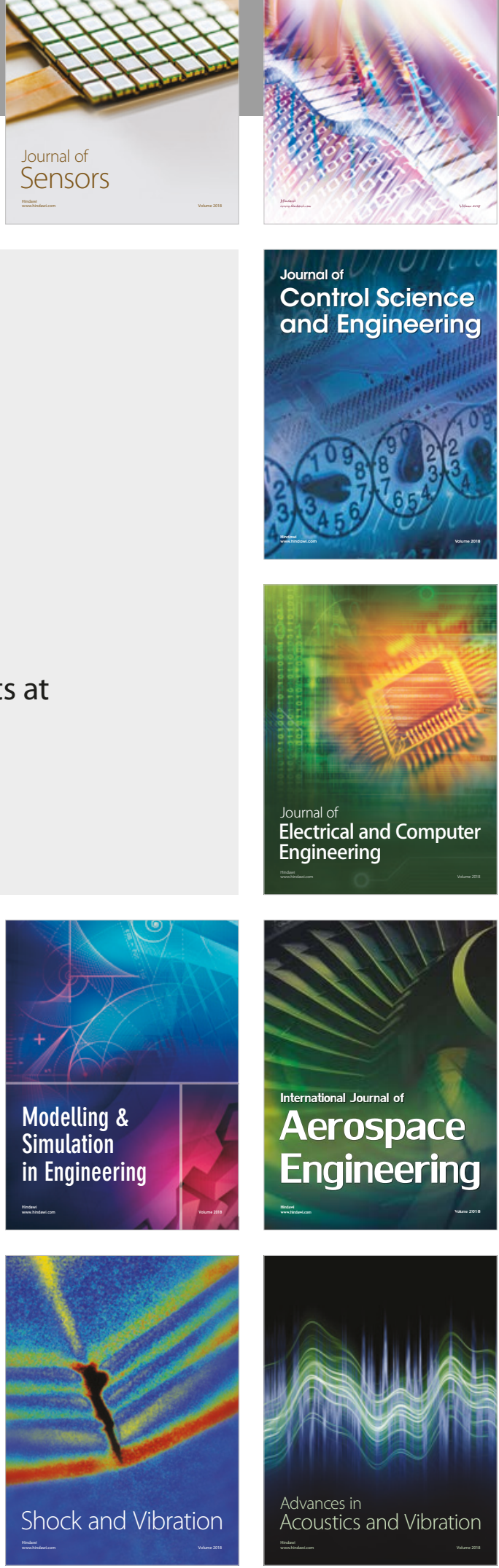